\title{
Qualidade de pimentões amarelos minimamente processados tratados com antioxidantes
}

\section{Quality of minimally processed yellow bell pepper treated with antioxidants}

\author{
Ricardo Alfredo Kluge ${ }^{1^{*}}$; Gabriela Maria Geerdink2; \\ Jaqueline Visioni Tezotto-Uliana ${ }^{2}$; Silce Adeline Danelon Guassi ${ }^{3}$; \\ Thais Queiroz Zorzeto ${ }^{4}$; Fabiana Fumi Cerqueira Sasaki ${ }^{5}$; Simone da Costa Mello ${ }^{6}$
}

\section{Resumo}

Os antioxidantes tem sido usados em produtos hortícolas vegetais como forma de reduzir a perda do valor nutricional e ampliar a vida útil. Este trabalho teve como objetivo avaliar o efeito de diferentes antioxidantes sobre a conservação das características qualitativas e microbiológicas de pimentões amarelos minimamente processados. Os pimentões foram submetidos a tratamentos com soluções de ácido ascórbico $1 \%$; ácido cítrico $1 \%$; ácido salicílico $0,5 \%$ e EDTA $2 \%$ e armazenados a $5^{\circ} \mathrm{C}$ e $90 \%$ UR durante 14 dias. A aplicação do ácido ascórbico permitiu a reposição das perdas deste ácido no produto e a manutenção do mesmo ao longo do armazenamento, enquanto que para os demais tratamentos houve redução do teor. O teor de carotenoides foi reduzido em aproximadamente $30 \%$ após o processamento mínimo em todos os tratamentos. A elevação da taxa respiratória e de produção de etileno foi atenuada com a aplicação dos três ácidos, sem efeito do EDTA. Os tratamentos não afetaram a microbiologia do produto, sendo que não foi verificada presença de Salmonella. A contagem de coliformes totais e termotolerantes, e de bactérias psicrotróficas ficaram abaixo do limite máximo permitido pela legislação vigente.

Palavras-chave: Capsicum annum, ácido ascórbico, ácido cítrico, ácido salicílico, EDTA

\footnotetext{
Abstract

Antioxidants have been used in vegetable in order to reduce the loss of nutritional value and extend the shelf life. The present study was carried out to evaluate the effect of different antioxidant compounds on the preservation of quality, microbiological and nutritional characteristics of fresh-cut yellow bell peppers. The bell peppers were submitted to treatments with solutions of $1 \%$ ascorbic acid; $1 \%$ citric acid; $0.5 \%$ salicylic acid and 2\% EDTA and stored at $5^{\circ} \mathrm{C}$ and $90 \% \mathrm{RH}$ for fourteen days. The ascorbic acid addition allowed the replacement of the ascorbic acid losses in the product and its maintenance during storage, whereas in the other treatments there was decrease in the content of this acid. The content of carotenoids was reduced by approximately $30 \%$ after processing in all treatments. The increase in

${ }^{1}$ Prof. do Dept ${ }^{\circ}$ de Ciências Biológicas, Escola Superior de Agricultura "Luiz de Queiroz", ESALQ/USP, Piracicaba, SP. E-mail:

${ }^{2}$ Discentes do Curso de Pós-Graduação em Fitotecnia da ESALQ/USP, Piracicaba, SP. E-mail: gmgeerdink@gmail.com; jaqueline.

${ }^{3}$ Discente do Curso de Pós-Graduação em Ciência dos Alimentos, ESALQ/USP, Piracicaba, SP. E-mail: sguassi@gmail.com

${ }^{4}$ Discente do Curso de Pós-Graduação em Engenharia Agrícola, FEAGRI/UNICAMP, Campinas, SP. E-mail: thais.zorzeto@

5 Pesquisadora da EMBRAPA Mandioca e Fruticultura, Cruz das Almas, BA. E-mail: fabiana.sasaki@embrapa.br

${ }^{6}$ Prof $^{a}$ do Dept ${ }^{0}$ de Produção Vegetal, ESALQ/USP, Piracicaba, SP. E-mail: scmello@usp.br
} rakluge@usp.br tezotto@usp.br feagri.unicamp.br

* Autor para correspondência 
respiratory rate and ethylene production was attenuated with the application of the three acids, without effect of EDTA. The treatments did not affect the microbiology of the product, and has not been verified presence of Salmonella. The count of total and fecal coliforms, and psychrotrophic bacteria were below the maximum allowed by legislation.

Key words: Capsicum annum, ascorbic acid, citric acid, salicylic acid, EDTA

\section{Introdução}

O pimentão (Capsicum annuum L.), pertencente à família Solanaceae, é uma hortaliça bastante popular, devido as suas características de coloração, aroma e sabor. O pimentão amarelo apresenta alto valor nutricional, caracterizado principalmente pelo seu teor de vitamina $C$, que é superior ao verificado nos pimentões vermelho e verde, e aqueles verificados em muitas frutas. O pimentão amarelo também é rico em vitamina A e minerais, como potássio e magnésio. A presença de carotenoides em seus tecidos confere benefícios a saúde humana, atuando como antioxidante e removedor de radicais livres, o que pode reduzir o risco do desenvolvimento de diversos tipos de câncer (MARÍN et al., 2004; NAVARRO et al., 2006).

Atualmente, há uma grande demanda pelos produtos minimamente processados, pelas características que apresentam, como estar disponível em porções menores, facilidade de utilização ou preparo, e qualidade. As operações do processamento mínimo, entretanto, causam danos mecânicos aos tecidos dos produtos, o que geralmente acelera a senescência e a deterioração, levando à descoloração e a perda do valor nutricional. Assim, geralmente os produtos minimamente processados possuem menor vida útil se comparado ao produto inteiro.

O crescimento da demanda pelos produtos minimamente processados tem estimulado o desenvolvimento de técnicas de conservação para a manutenção de sua qualidade, com impactos no aumento da vida útil. Estas técnicas incluem a refrigeração, obrigatória para estes produtos desde o preparo até durante a comercialização, e outras técnicas associadas, como aplicação de atmosfera modificada, uso de antioxidantes, cloreto de cálcio entre outras substâncias (AGUILA et al., 2006; 2008; CONESA et al., 2007; EVANGELISTA et al., 2008; GONZALEZ-AGUILAR et al., 2004; KLUGE et al., 2008; MANOLOPOULOU; LAMBRINOS; XANTHOPOULOS, 2012; SENESI et al., 2000; VITTI et al., 2005; 2010).

Vários compostos antioxidantes, como os ácidos ascórbico, cítrico e salicílico, e o etilenodiamino-tetracético (EDTA), tem sido testadas em produtos minimamente processados com o objetivo de evitar perdas de coloração, sabor, aroma e qualidade nutricional. Com exceção do ácido salicílico, os demais produtos citados fazem parte do Compêndio da Legislação Brasileira de aditivos alimentares, disponibilizado pela Agência Nacional de Vigilância Sanitária (ANVISA) para uso nos produtos hortícolas (BRASIL, 2013).

O ácido L-ascórbico e seus sais neutros, isoladamente ou em combinação com ácido cítrico, são utilizados como antioxidantes em frutas, hortaliças vegetais e sucos para prevenir o escurecimento e outras reações oxidativas. $\mathrm{O}$ ácido ascórbico atua na redução da $o$-benzoquinona a $o$-diidroxifenol e/ou pela inativação irreversível da polifenoloxidase (PPO). Adicionalmente, remove oxigênio do meio, transformando-se no ácido dehidroascórbico, e promovendo a regeneração de antioxidantes, além de atuar sinergisticamente com agentes complexantes (PINELI, 2004). O ácido ascórbico, além de ser seguro para o consumo humano, pode incrementar o conteúdo de vitamina $\mathrm{C}$ em frutas e hortaliças, como evidenciado por Carvalho e Lima (2002) em kiwis, e Evangelista et al. (2009) em couve chinesa. Aguila et al. (2008) aplicaram ácido ascórbico em rabanete minimamente processado e verificaram aumentos significativos neste ácido durante a conservação refrigerada. 
O ácido cítrico é o principal ácido orgânico encontrado em vegetais. Atua como quelante e sinergisticamente com ácido ascórbico e eritórbico e seus sais neutros (PINELI, 2004). Apresenta diminuição na atividade da polifenoloxidase, devido ao abaixamento do $\mathrm{pH}$ do meio e pela complexação com o cobre do centro ativo da enzima.

O ácido cítrico aplicado em beterraba minimamente processada diminuiu a respiração do produto e manteve mais altos os níveis de betalaínas (KLUGEetal., 2008).Aguila etal.(2008) observaram que rabanetes minimamente processados e tratados com ácido cítrico apresentaram aumento no teor de sólidos solúveis, mas não houve efeito sobre o escurecimento das raízes.

O EDTA é outro antioxidante bastante testado, atuando complexando cobre e íons ferro, por meio de um par não conjugado de elétrons em suas estruturas moleculares (PINELI, 2004). Melo e Vilas Boas (2006) verificaram que o EDTA foi eficiente para a redução do escurecimento enzimático de banana maçã minimamente processada. Jesus et al. (2008) verificaram que o EDTA diminuiu o escurecimento da parte interna de quiabo minimamente processado, enquanto que Evangelista et al. (2009) observaram manutenção dos teores de vitamina $\mathrm{C}$ em couve chinesa minimamente processada.

O ácido salicílico, um derivado do ácido hidrobenzóico, é considerado um hormônio vegetal envolvido em várias fases do crescimento e desenvolvimento. É um ácido fenólico que, quando aplicado, pode ativar sistemas antioxidantes decorrentes de estresses bióticos ou abióticos (SENARATNA et al., 2004), sendo pouco utilizado como antioxidante em produtos minimamente processados. Rao, Gol e Shah (2011) verificaram que o ácido salicílico em pimentão mantido inteiro a $10^{\circ} \mathrm{C}$ ou $25^{\circ} \mathrm{C}$ reduziu a perda de firmeza e manteve a qualidade dos frutos em comparação aos frutos não tratados.

O pimentão minimamente processado tem sido pouco estudado e já é um produto disponível do mercado brasileiro e de outros países. O conhecimento dos efeitos de antioxidantes nesta hortaliça pode trazer benefícios para a extensão de sua vida útil e manutenção da qualidade nutricional e segurança alimentar. Desse modo, o objetivo do trabalho foi avaliar o efeito de diferentes compostos antioxidantes sobre a conservação das características qualitativas, microbiológicas e nutricionais de pimentões amarelos minimamente processados e mantidos sob refrigeração.

\section{Material e Métodos}

Pimentões 'Sunboy', cultivados em ambiente protegido (estufa), foram colhidos na região de Indaiatuba (SP) e transportados para o Laboratório de Fisiologia e Bioquímica Pós-colheita da ESALQ/ USP em Piracicaba (SP). A colheita dos frutos ocorreu 110 dias após o plantio, quando adquiriram $50 \%$ de coloração amarela. Os pimentões foram previamente selecionados para a homogeneização do lote quanto à coloração ( $50 \%$ de cor amarela), formato (quadrado) e ausência de danos mecânicos, pré-lavados com água corrente submetidos ao processamento mínimo em câmara fria a $10^{\circ} \mathrm{C}$. Inicialmente os pimentões inteiros foram imersos durante 5 minutos em água clorada (200 $\mathrm{mg} \mathrm{L}^{-1}$ de cloro ativo) resfriada a $10^{\circ} \mathrm{C}$. $\mathrm{O}$ pedúnculo e as sementes foram removidos e as hortaliças foram cortadas em rodelas de $10 \mathrm{~mm} \mathrm{( \pm}$ $1 \mathrm{~mm})$. As rodelas foram sanificadas por 5 minutos em água clorada (200 $\mathrm{mg} \mathrm{L}^{-1}$ de cloro ativo), sendo em seguida escorridas, para a retirada do excesso de umidade.

As rodelas foram submetidas aos seguintes tratamentos: ácido ascórbico $1 \%$; ácido cítrico $1 \%$; ácido salicílico $0,5 \%$; etileno-diamino-tetracético (EDTA) 2\%, e controle (água destilada), sendo $1,2 \mathrm{~kg}$ de pimentão imersos em $20 \mathrm{~L}$ de solução antioxidante. A imersão foi feita em caixas plásticas de $50 \times 36,5 \times 26,5 \mathrm{~cm}^{3}$, durante 5 minutos. Após os tratamentos, foi realizada a centrifugação a 2200rpm durante 40 segundo, para a retirada do excesso de umidade. Em seguida, $120 \mathrm{~g}$ do produto 
minimamente processado foi acondicionado em bandejas de poliestireno expandido recoberta filme de policloreto de vinila (PVC). As embalagens foram armazenadas em câmara a $5 \pm 1{ }^{\circ} \mathrm{C}$ e $90 \pm 5 \%$ UR durante 14 dias, sendo analisadas logo após o processamento (caracterização) e a cada 2 dias até o final do armazenamento.

As seguintes análises foram realizadas: a) Perda de massa: por pesagem inicial e final das bandejas, com os resultados expressos em porcentagem; b) $p H$ : por leitura direta do suco de pimentão em peagâmetro digital; c) Acidez titulável (AT): com a utilização de $10 \mathrm{~mL}$ do suco diluídos com $90 \mathrm{~mL}$ de águadestilada, que foititulado potenciometricamente com $\mathrm{NaOH}$ a $0,1 \mathrm{~N}$ até $\mathrm{pH} 8,10$ e os resultados expressos em \% de ácido cítrico; d) Teor de sólidos solúveis (SS): determinado em refratômetro digital, com correção automática de temperatura para $20^{\circ} \mathrm{C}$ e os resultados expressos em ${ }^{\circ} \mathrm{Brix}$; e) Teor de ácido ascórbico (AA): uma alíquota de $10 \mathrm{~mL}$ de suco foi diluída com $50 \mathrm{~mL}$ de ácido oxálico, e em seguida titulado com o 2,6-diclorofenol indolfenol-sódico (DCFI) até a coloração rosada persistente por 15 segundos, com os resultados expressos em $\mathrm{mg}$ de ácido ascórbico por $100 \mathrm{~g}$; f) Teor de carotenoides: foi determinado pela metodologia de Lichtenthaler (1987), conforme a seguir: a quantidade de $0,3 \mathrm{~g}$ de amostra de pimentão minimamente processado foi triturada e adicionado $5 \mathrm{~mL}$ de acetona $80 \%$ e depois centrifugada por 15 minutos na velocidade de $12000 \mathrm{xg}$ a $4^{\circ} \mathrm{C}$. Logo após, foi feita a leitura em espectrofotômetro a 470, 645 e $663 \mathrm{~nm}$. O teor de carotenoides foi determinado pela equação: Carot $=\left[1000 \mathrm{~A}_{470}-1,82\left(12,25 \mathrm{~A}_{663}-2,79 \mathrm{~A}_{645}\right)\right.$ - 85,02(21,50 $\left.\left.\mathrm{A}_{645}-5,10 \mathrm{~A}_{663}\right)\right] / 198$, onde $\mathrm{A}_{470}=$ absorbância a $470 \mathrm{~nm}, \mathrm{~A}_{645}=$ absorbância a $645 \mathrm{~nm}$ e $\mathrm{A}_{663}=$ absorbância a $663 \mathrm{~nm}$. Os resultados foram expressos em $\mathrm{mg} \mathrm{g}^{-1}$; g) Produção de etileno e taxa respiratória: aproximadamente $50 \mathrm{~g}$ do pimentão processado foram acondicionados em recipientes herméticos de $600 \mathrm{~mL}$, permanecendo fechados por aproximadamente 30 minutos. Foram injetadas $0,5 \mathrm{~mL}$ do gás de cada recipiente em um cromatógrafo a gás marca Thermo Electron Corporation, modelo Trace GC Ultra, equipado com dois detectores de ionização de chama (FID) regulados para $250^{\circ} \mathrm{C}$, dois injetores regulados para $100^{\circ} \mathrm{C}$, duas colunas Porapack N (coluna $\mathrm{CO}_{2}-4 \mathrm{~m}$ e fluxo de $25 \mathrm{~mL}$

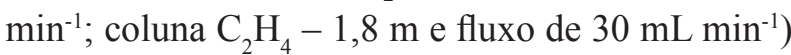
reguladas para $100^{\circ} \mathrm{C}$ e um metanador regulado para $350^{\circ} \mathrm{C}$. A produção de etileno foi expressa em $\mu \mathrm{L}$ $\mathrm{C}_{2} \mathrm{H}_{4} \mathrm{~kg}^{-1} \mathrm{~h}^{-1}$ e a taxa respiratória, quantificada pela produção de $\mathrm{CO}_{2}$, expressa em $\mathrm{mL} \mathrm{CO}_{2} \mathrm{~kg}^{-1} \mathrm{~h}^{-1}$.

A microflora contaminante dos pimentões minimamente processados foi avaliada pela contagem total de bactérias psicrotróficas, número mais provável (NMP) de coliformes totais $\mathrm{e}$ termotolerantes (coliformes a $45^{\circ} \mathrm{C}$ ) e detecção de Salmonella em $25 \mathrm{~g}$ do produto, conforme a Resolução da Diretoria Colegiada (RDC) n ${ }^{\circ} 12$ de 2001, da Agência Nacional de Vigilância Sanitária (ANVISA), legislação vigente (BRASIL, 2001). As análises para contagem de bactérias psicrotróficas e para o NMP de coliformes foram efetuadas imediatamente após o processamento das hortaliças e nos dias 6 e 14 de armazenamento. A contagem total de bactérias psicrotróficas foi realizada por meio da técnica de plaqueamento em profundidade em meio Agar Padrão para Contagem (PCA). As placas foram incubadas a $7^{\circ} \mathrm{C}$ por 10 dias. $\mathrm{O}$ NMP de coliformes totais e termotolerantes foram determinados pela técnica dos Tubos Múltiplos. O número de tubos positivos em cada série do teste confirmativo foi confrontado com a Tabela da Associação Brasileira de Normas Técnicas (MB 3463). Para a detecção de Salmonella foi utilizado o Kit 1-2 Test (Biocontrol/USA) segundo as normas do fabricante.

O delineamento experimental utilizado foi o inteiramente casualizado, em esquema fatorial (5x8), sendo cinco tratamentos e 8 períodos de análise, incluindo o tempo zero (caracterização). Foram utilizadas 4 bandejas de $120 \mathrm{~g}$ de pimentão minimamente processado por parcela. Os resultados obtidos foram submetidos à análise de variância (ANOVA), sendo as médias comparadas pelo teste 
de Tukey $(P \leq 0,05)$. A análise estatística foi realizada utilizando-se o software estatístico SISVAR. Para as análises microbiológicas, os resultados obtidos foram comparados com a RDC no 12 de 2001, da ANVISA (BRASIL, 2001).

\section{Resultados e Discussão}

A perda de massa foi crescente durante o período de armazenamento, não havendo diferença entre os tratamentos (Figura 1A). A perda de água é um dos principais fatores de deterioração dos produtos minimamente processados, devido à maior superfície de exposição e da quebra a barreira natural contra a evaporação da água a partir do interior do produto (CHITARRA; CHITARRA, 2007). Ao final do armazenamento a perda de massa atingiu valores entre 1,2 a 1,5\%, não tendo sido observado murchamento visível nos pimentões minimamente processados. Isso indica que a temperatura, a umidade relativa e o uso de embalagem utilizadas no experimento protegeram o produto contra a desidratação.

Não houve diferença significativa entre os tratamentos em relação ao pH e à AT. No entanto, ao longo do período analisado, houve queda do $\mathrm{pH}$, com subsequente aumento a partir do $10^{\circ}$ dia de armazenamento (Figura 1B), comportamento este acompanhado pelo aumento inicial e posterior declínio da AT (Figura 1C). A acidificação dos pimentões logo após o processamento pode ter sido decorrente do aumento da concentração de dióxido de carbono intracelular resultante do aumento das taxas respiratórias. $\mathrm{O}$ aumento do $\mathrm{pH}$ no final do período de armazenamento também foi observado por Izumi, Watada e Douglas (1996), os quais relacionaram tal fato com o aumento da microbiota contaminante.

O teor de SS apresentou uma queda inicial dos valores, no segundo dia, tendo após permanecido a valores aproximadamente constantes até o final do armazenamento, não havendo diferença entre os tratamentos (Figura 1D). Em se tratando de um fruto climatérico não é de se esperar grandes oscilações nesta variável, mas considerando o estresse provocado pelo processamento pode haver consumo de substratos respiratórios, o que realmente parece ter ocorrido ao obervarmos a elevação da respiração ocorrida no dia seguinte ao processamento (Figura 2A).

Os pimentões minimamente processados tratados com ácido ascórbico apresentaram aumento desse ácido após o tratamento e mantiveram esse teor mais elevado durante o armazenamento (Figura 1E). Wiley (1994) observou que, em vegetais minimamente processados, o ácido ascórbico é o principal antioxidante para a prevenção de reações oxidativas e que, portanto, deve ser empregado nestes produtos, uma vez que o aumento da atividade de enzimas oxidativas resulta na rápida perda da atividade vitamínica. Aguila et al. (2008) observaram que rabanetes minimamente processados e tratados com ácido ascórbico obtiveram incremento no teor desse ácido durante o armazenamento refrigerado. Carvalho e Lima (2002) verificaram que kiwis minimamente processados e tratados com ácido ascórbico mantiveram o teor de vitamina $\mathrm{C}$ em $25 \%$ mais elevado dos os tratados com ácido cítrico. Nos demais tratamentos do presente trabalho foi observado declínio progressivo no teor de ácido ascórbico durante o armazenamento refrigerado (Figura 1E), de aproximadamente 10\%, em média. A perda de compartimentalização oriunda do corte dos produtos minimamente processados pode ocasionar maior perda de ácido ascórbico, devido à oxidação direta, por meio da atividade da oxidase do ácido ascórbico, ou indireta, devido à atividade de peroxidase, polifenoloxidase e citocromo oxidase (BRECHT, 1995; MAIA et al., 2008). 
Figura 1. Efeito de tratamentos com antioxidante sobre a perda de massa (A), pH (B), acidez (C), sólidos solúveis (D), teor de ácido ascórbico (E) e teor de carotenoides (F) em pimentão 'Sunboy' minimamente processado e armazenado a $5^{\circ} \mathrm{C}$ e $90 \%$ UR. Barras verticais representam o desvio padrão da média ( $\left.\mathrm{n}=4\right)$.
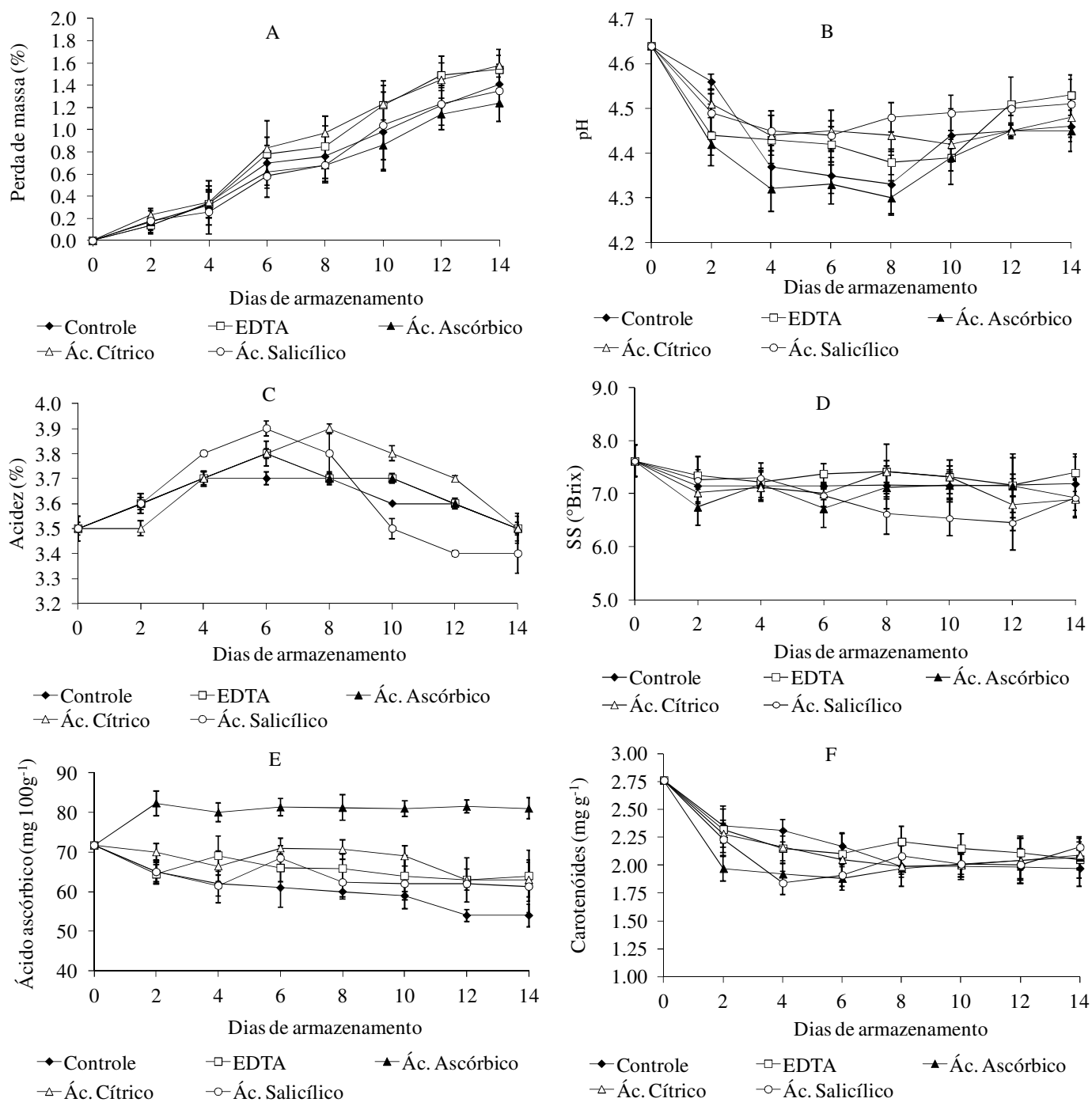

Fonte: Elaboração dos autores. 
Figura 2. Efeito de tratamentos com antioxidante sobre a taxa respiratória (A) e produção de etileno (B) em pimentão 'Sunboy' minimamente processado e armazenado a $5^{\circ} \mathrm{C}$ e $90 \%$ UR. Barras verticais representam o desvio padrão da média $(\mathrm{n}=4)$.
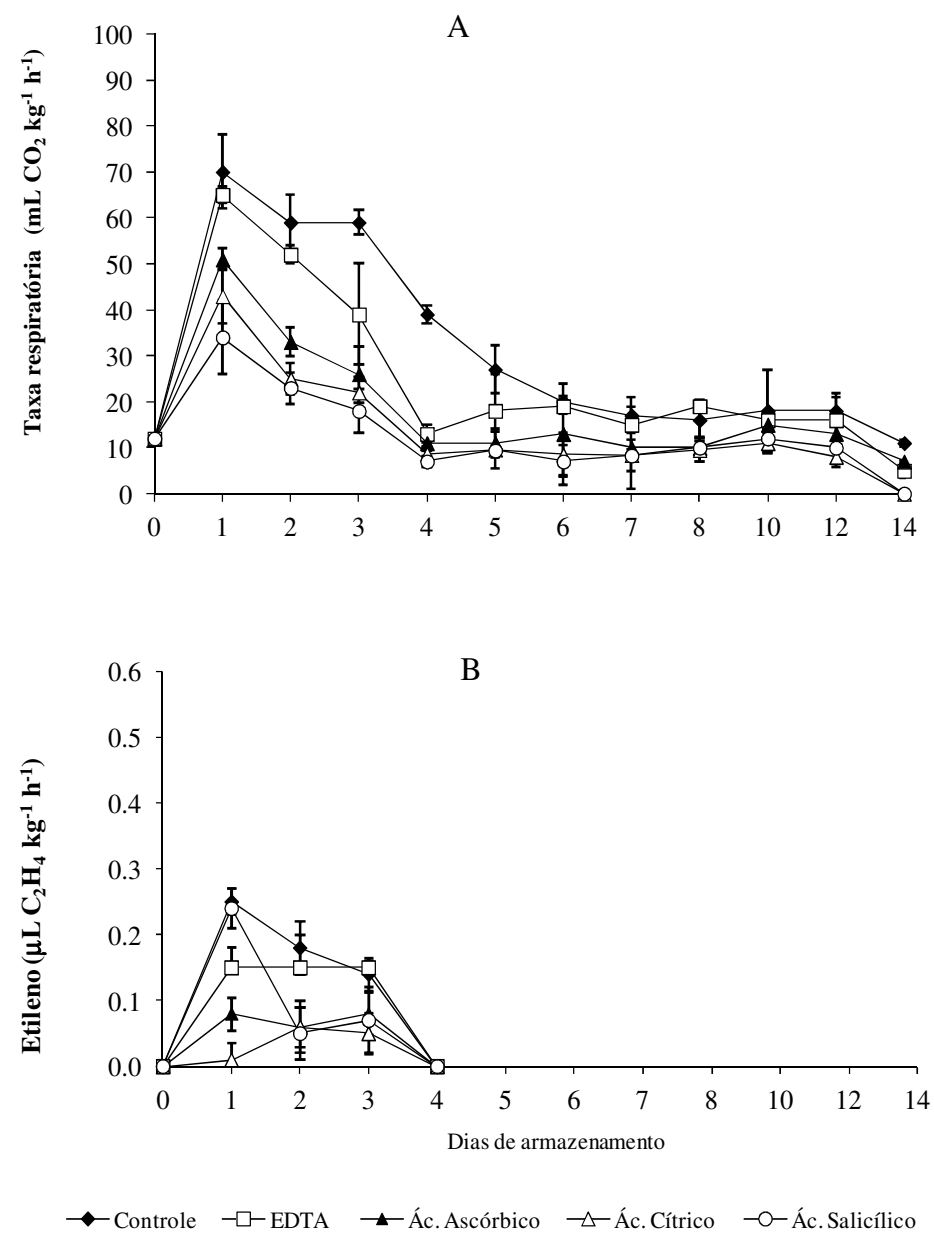

Fonte: Elaboração dos autores.

Para o teor de carotenoides totais houve redução logo a partir do $2^{\circ}$ dia de armazenamento (Figura $1 \mathrm{~F})$, representando uma perda de quase $30 \% \mathrm{em}$ relação ao valor inicial (antes do processamento). Em frutos climatéricos, como o pimentão, o processo de senescência leva a uma série de degradações oxidativas, entre elas a degradação de pigmentos. Estas degradações são decorrentes de estímulos a atividade enzimática, que no caso de carotenoides, deve-se à atividade de lipoxigenase e peroxidase, na presença de oxigênio e outros cofatores (DORANTES-ALVAREZ; CHIRALT, 2000; UENOJO; MARÓSTICA JUNIOR; PASTORE,
2007). Em pimentões amarelos, a retenção do teor de carotenoides é fundamental para a manutenção de suas características nutricionais, pois constituem fontes de antioxidantes naturais. No presente experimento, a queda nos teor de carotenoides foi devido ao estresse provocado pelo corte, que faz aumentar as reações de oxidações e acelera a própria senescência do fruto, sendo que nenhum dos antioxidantes testados foi capaz de evitar a perda ou manter os níveis iniciais de carotenoides.

Independente do tratamento utilizado houve aumento significativo da taxa respiratória nos primeiros dias de armazenamento (Figura 2A), 
sendo que os tratamentos controle e EDTA apresentaram taxas respiratórias próximas a $70 \mathrm{~mL}$ de $\mathrm{CO}_{2} \mathrm{~kg}^{-1} \mathrm{~h}^{-1}$. Nos pimentões tratados com ácido cítrico, ascórbico ou salicílico também houve pico, mas com intensidade menor (30 a $50 \mathrm{~mL}$ de $\mathrm{CO}_{2}$ $\mathrm{kg}^{-1} \mathrm{~h}^{-1}$ ). A redução na taxa respiratória provocada pelo uso dos ácidos salicílico e cítrico também foi observada por Kluge et al. (2008) e Kluge, Picoli e Aguila (2010) em beterraba minimamente processada. Os autores relataram que o uso de ácidos como aditivos na conservação pós-colheita de alimentos resulta na redução do $\mathrm{pH}$ citosólico, o que afeta a atividade das enzimas glicolíticas e diminui a taxa respiratória.

Os incrementos iniciais na taxa respiratória de produtos minimamente processados podem ser atribuídos ao estresse provocado pelo corte, que causa descompartimentalização celular e libera substratos do metabolismo respiratório para os complexos enzimáticos (PURVIS, 1997). Nos dias subsequentes aos picos, houve redução da taxa respiratória até valores próximos a $10 \mathrm{~mL} \mathrm{CO} \mathrm{kg}^{-1}$ $\mathrm{h}^{-1}$, valores estes semelhantes aos da caracterização (antes do processamento mínimo). A redução progressiva subsequente aos picos na respiração se deve ao fato de que os substratos respiratórios, possivelmente, pararam de reagir com as enzimas presentes nas células da superfície do corte, de forma que a taxa respiratória mais baixa observada a partir do quarto dia de armazenamento pode ser resultante das células localizadas abaixo da superfície danificada pelo corte. Os picos e subsequentes declínios respiratórios também foram verificados em produtos minimamente processados em estudos de outros autores (GONZALEZ-AGUILAR et al., 2004; KLUGE et al., 2008; VITTI et al., 2003; 2004; 2005; 2010; SENESI et al., 2000).

Houve produção de etileno a partir de um dia após o processamento mínimo em todos os tratamentos, sendo que esta produção ocorreu até o terceiro dia, não tendo sido detectado etileno a partir do quarto dia (Figura 2B). Estas produções quantificadas podem ser consideradas baixas, e são decorrentes de respostas ao corte, que inclui entre outras, o aumento na produção de etileno, devido ao acúmulo de ACC (ácido 1-aminociclopropano-1-carboxílico) e maior atividade da ACC sintase nos tecidos injuriados (BRECHT, 1995). Estes incrementos na taxa de produção de etileno observados no presente trabalho são oriundos, possivelmente, das células superficialmente danificadas pelo corte. Gonzalez -Aguilar et al. (2004) também verificaram produção de etileno logo após o corte de pimentão minimamente processado, com posterior declínio em níveis não detectáveis. A aplicação dos ácidos (cítrico, ascórbico e salicílico) atenuou o incremento na produção de etileno em relação ao controle e ao EDTA. Isso explica, em parte, as menores taxas respiratórias observadas nos tratamentos com os ácidos (Figura 2A).

Em relação às análises microbiológicas não foi constatada presença de Salmonella em $25 \mathrm{~g}$ de produto minimamente processado, como recomenda pela RDC 12 da ANVISA (BRASIL, 2001). As análises de coliformes termotolerantes a $45^{\circ} \mathrm{C}$ resultaram em valores bem abaixo do máximo estabelecido na legislação para segurança alimentar, que é de $10^{2}$ (Tabela 1). Para os coliformes totais os valores iniciais foram de $<3,0 \mathrm{NMP} \mathrm{g}^{-1}$ sendo que no final de 14 dias de armazenamento os valores obtidos foram de, no máximo, $>1,1 \times 10^{3}$. A legislação estabelece o limite máximo de $10^{5}$ para coliformes totais, portanto, os resultados obtidos para estes microrganismos foram bem abaixo do máximo permitido. Para as bactérias psicrotróficas houve um incremento na população ao longo do armazenamento atingindo valores entre $10^{2}$ e $10^{4}$ ao final de 14 dias de armazenamento (Tabela 1), valores considerados abaixo do mínimo estabelecido na legislação, que é de $10^{5}$. 
Tabela 1. Coliformes totais, coliformes termotolerantes e bactérias psicotróficas em pimentão 'Sunboy' minimamente processado e armazenado a $5^{\circ} \mathrm{C}$ e $90 \% \mathrm{UR}$.

\begin{tabular}{|c|c|c|c|}
\hline \multirow[b]{2}{*}{ Tratamentos* } & \multicolumn{3}{|c|}{ Dias de armazenamento } \\
\hline & 0 & 6 & 14 \\
\hline & \multicolumn{3}{|c|}{----- Coliformes totais $\left(\mathrm{NMP} \mathrm{g}^{-1}\right)$------ } \\
\hline Controle & $<3$ & $0,7 \times 10$ & $3,0 \times 10$ \\
\hline EDTA & $<3$ & $9,3 \times 10$ & $>1,1 \times 10^{3}$ \\
\hline AA & $<3$ & $<3$ & $2,4 \times 10^{2}$ \\
\hline $\mathrm{AC}$ & $<3$ & $0,4 \times 10$ & $>1,1 \times 10^{3}$ \\
\hline \multirow[t]{2}{*}{ AS } & $<3$ & $0,6 \times 10$ & $>1,1 \times 10^{3}$ \\
\hline & \multicolumn{3}{|c|}{----- Coliformes termotolerantes $\left(\mathrm{NMP} \mathrm{g}^{-1}\right)$----- } \\
\hline Controle & $<3$ & $0,7 \times 10$ & $<3$ \\
\hline EDTA & $<3$ & $9,3 \times 10$ & $0,4 \times 10$ \\
\hline AA & $<3$ & $<3$ & $<3$ \\
\hline $\mathrm{AC}$ & $<3$ & $<3$ & $<3$ \\
\hline \multirow{2}{*}{ AS } & $<3$ & $0,4 \times 10$ & $0,7 \times 10$ \\
\hline & \multicolumn{3}{|c|}{----- Bactérias psicrotróficas (UFC $\mathrm{g}^{-1}$ ) ----- } \\
\hline Controle & $<10$ est. & $9,5 \times 10$ & $2,2 \times 10^{2}$ \\
\hline EDTA & $<10$ est. & $2,3 \times 10^{3}$ & $2,9 \times 10^{3}$ \\
\hline AA & $<10$ est. & $1,3 \times 10^{2}$ & $3,8 \times 10^{2}$ \\
\hline $\mathrm{AC}$ & $<10$ est. & $6,2 \times 10^{2}$ & $1,7 \times 10^{4}$ \\
\hline AS & $<10$ est. & $1,8 \times 10^{3}$ & $9,7 \times 10^{4}$ \\
\hline
\end{tabular}

* EDTA = etileno-diamino-tetracético; AA = ácido ascórbico, AC = ácido cítrico, AS = ácido salicílico.

Fonte: Elaboração dos autores.

Os resultados de microbiologia encontrados mostram que os procedimentos no processamento mínimo foram realizados dentro dos padrões de segurança e higiene alimentar, uma vez que estes microrganismos são associados há contaminação na manipulação de alimentos. Vale ressaltar que a manutenção da cadeia de frio, desde o preparo do produto até o consumidor final, bem como estudos voltados para o desenvolvimento de tecnologias de conservação, são fundamentais para manter a segurança de alimentos e a qualidade dos produtos minimamente processados.

\section{Conclusão}

O presente trabalho indicou que o ácido ascórbico é o antioxidante mais adequado de ser utilizado. A sua aplicação foi útil para a preservação desse ácido nos tecidos de pimentão amarelo minimamente processado, além de reduzir a atividade respiratória e manter os padrões de segurança e higiene desse produto. Verificou-se também, que nenhum dos antioxidantes testados impediu a redução no teor de carotenóides, após o processamento, e independente do tratamento o pimentão processado pode ser comercializado por 14 dias.

\section{Referências}

AGUILA, J. S.; SASAKI, F. F.; HEIFFIG, L. S.; ORTEGA, E. M. M.; TREVISAN, M. J.; KLUGE, R. A. Antioxidants in fresh cut radishes cold stored. Brazilian Archives of Biology and Technology, Curitiba, v. 51, n. 6, p. 1217-1223, 2008.

AGUILA, J. S.; SASAKI, F. F.; HEIFFIG, L .S.; ORTEGA, E. M. M.; JACOMINO, A. P.; KLUGE, R. A. Fresh-cut radish using different cut types and storage temperatures. Postharvest Biology and Technology, Wageningen, v. 40, n. 2, p. 149-154, 2006. 
BRASIL. Ministério da Saúde. Agência Nacional de Vigilância Sanitária. Resolução RDC 12 de 2 de janeiro de 2001. Aprova o regulamento técnico sobre padrões microbiológicos para alimentos. Diário Oficial [da] República Federativa do Brasil, Brasília, DF, n. 7-E, 10 jan. 2001. Seção 1.17, p. 45-53.

Ministério da Saúde. Agência Nacional de Vigilância Sanitária. Compêndio da legislação brasileira de aditivos alimentares. Aprova uso de produtos como aditivos para alimentos. Diário Oficial [da] União, Brasília, DF, 24 set. 2013. Seção 1, p. 45. Disponível em: http://portal.anvisa.gov.br/wps/wcm/connect/ a6809d8047457a1c86c0d63fbc4c6735/Compendio marco_2011.pdf?MOD=AJPERES. Acesso em: 24 jun. 2013.

BRECHT, J. K. Physiology of lightly processed fruits and vegetables. HortScience, Alexandria, v. 30, n. 1, p. 18-22, 1995.

CARVALHO, A. V.; LIMA, L. C. O. Qualidade de kiwis minimamente processados e submetidos a tratamento com ácido ascórbico, ácido cítrico e cloreto de cálcio. Pesquisa Agropecuária Brasileira, Brasília, v. 37, n. 5, p. 679-685, 2002.

CHITARRA, M. I. F.; CHITARRA, A. B. Processamento mínimo de alface. In: MORETTI, C. L. Manual de processamento mínimo de frutas e hortaliças. Brasília: Embrapa/SEBRAE, 2007. p. 301-341.

CONESA, A.; VERLINDEN, B. E.; ARTÉSHERNÁNDEZ, F.; NICOLA, B.; ARTÉS, F. Respiration rates of fresh-cut bell peppers under supertamospheric and low oxygen with or without high carbon dioxide. Postharvest Biology and Technology, Wageningen, v. 4, n. 1, p. 81-88, 2007.

DORANTES-ALVAREZ, L.; CHIRALT, A. Color of minimally processed fruits and vegetable as affected by some chemical and biochemical changes. In: ALZAMORA, S. M.; TAPIA, M. S.; LÓPEZ-MALO, A. Minimally processed fruits and vegetables: fundamental aspects and applications. Gaithersburg: Ed. Aspen Publication, 2000. p. 111-126.

EVANGELISTA, R. M.; GODOY, A. R.; CARDOSO, A. I. I.; VIEITES, R. L. Qualidade de pimentão 'Rubia' minimamente processado e armazenado sob refrigeração. Ceres, Viçosa, v. 55, n. 4, p. 338-343, 2008.

EVANGELISTA, R. M.; VIEITES, R. L.; CASTRO, P. S.; RALL, V. L. Qualidade de couve-chinesa minimamente processada e tratada com diferentes produtos. Ciência e Tecnologia de Alimentos, Campinas, v. 29, n. 2, p. 324332, 2009.
GONZALEZ-AGUILAR, G. A.; AYALA-ZAVALA, J. F.; RUIZ-CRUZ, A. S.; ACEDO-FELIX, E.; DÍAZCINCO, M. E. Effect of temperature and modified atmosphere packaging on overall quality of fresh-cut bell peppers. LWT - Food Science and Technology, Zürich, v. 37, n. 7, p. 817-826, 2004.

IZUMI, H.; WATADA, A. E.; DOUGLAS, W. Low $\mathrm{O}_{2}$ atmospheres affect storage quality of zucchini squash slices treated with calcium. Journal of Food Science, London, v. 61, n. 2, p. 317-321, 1996.

JESUS, M. M. S. de; CARNELOSSI, M. A. G.; SANTOS, S. F.; NARAIN, N.; CASTRO, A. A. Inibição do escurecimento enzimático de quiabo minimamente processado. Revista Ciência Agronômica, Fortaleza, v. 39 , n. 4, p. 524-530, 2008.

Kluge, R. A.; PICOLI, A. A.; AGUILA, J. S. Respiração e produção de etileno em beterrabas inteiras e minimamente processadas submetidas a tratamentos com etileno e biorreguladores. Horticultura Brasileira, Brasília, v. 28, n. 1, p. 54-57, 2010.

KLUGE, R. A.; VITTI, M. C. D.; SASAKI, F. F.; JACOMINO, A. P.; MORETTI, C. L. Respiratory activity and pigment metabolism in fresh-cut beet roots treated with citric acid. Horticultura Brasileira, Brasília, v. 26 , n. 4, p. 520-523, 2008.

LICHTENTHALER, H. K. Chlorophylls and carotenoids: pigments of photosynthetic biomembranes. Methods in Enzymology, San Diego, v. 148, n. 22, p. 350-382, 1987.

MAIA, G. E. G.; PASQUI, S. C.; LIMA, A. da S.; CAMPOS, F. M. Determinação dos teores de vitamina $\mathrm{C}$ em hortaliças minimamente processadas. Alimentos e Nutrição, Araraquara, v. 19, n. 3, p. 329-335, 2008.

MANOLOPOULOU, H.; LAMBRINOS, G.; XANTHOPOULOS, G. Active modified atmosphere packaging of fresh-cut bell peppers: effect on quality indices. Journal of Food Research, v. 1, n. 3, p. 148-158, 2012.

MARÍN, A.; FERRERES, F.; TOMÁS-BARBERÁN, F. A.; GIL, M. I. Characterization and quantitation of antioxidant constituents of sweet pepper (Capsicum annuum L.). Journal of Agriculture and Food Chemistry, Davis, v. 52, n. 12, p. 3861-3869, 2004.

MELO, A. A. M.; VILAS BOAS, E. V. B. Inibição do escurecimento enzimático de banana maçã minimamente processada. Ciência e Tecnologia de Alimentos, Campinas, v. 26, n. 1, p. 110-115, 2006. 
NAVARRO, J.; FLORES, P.; GARRIDO, C.; MARTINEZ, V. Changes in the contents of antioxidant compounds in pepper fruits at different ripening stages, as affected by salinity. Food Chemistry, London, v. 96, n. 1, p. 66-73, 2006.

PINELI, L. L. O. Processamento mínimo de batata. In: ENCONTRONACIONALSOBREPROCESSAMENTO MÍNIMO DE FRUTAS E HORTALIÇAS, 3., 2004, Viçosa. Palestras... Viçosa: UFV, 2004. p. 71-81.

PURVIS, A. C. The role of adaptive enzymes in carbohydrates oxidation by stressed and senescing plant tissues. HortScience, Alexandria, v. 32, n. 7, p. 1165 1168, 1997.

RAO, T. V. R.; GOL, N. B.; SHAH, K. K. Effect of postharvest treatments and storage temperatures on the quality and shelf life of sweet pepper (Capsicum annum L.). Scientia Horticulturae, Amsterdam, v. 132, n. 1, p. 18-26, 2011.

SENARATNA, T.; TOUCHELL, D.; BUNN, E.; DIXON, K. Acetyl salicylic acid (Aspirin) and salicylic acid induce multiple stress tolerance in bean and tomato plants. Plant Growth Regulation, Pietermaritzburg, v. 30, n. 2, p. 157-161, 2004.

SENESI, E.; PRINZIVALLI, C.; SALA, M.; GENNERI, M. Physicochemical and microbiological changes in fresh-cut green bell peppers as affected by packaging and storage. Italian Journal of Food Science, Pinerolo, v. 12, n. 1, p. 55-64, 2000.
UENOJO, M.; MARÓSTICA JUNIOR, M. R.; PASTORE, G. M. Carotenóides: propriedades, aplicações e biotransformação para formação de compostos de aroma. Quimica Nova, São Paulo, v. 30, n. 3, p. 616-622, 2007.

VITTI, M. C. D.; KLUGE, R. A.; GALlO, C. R.; SCHIAVINATO, M. A.; MORETTI, C. L.; JACOMINO, A. P. Aspectos fisiológicos e microbiológicos de beterrabas minimamente processadas. Pesquisa Agropecuária Brasileira, Brasília, v. 39, n. 10, p. $1027-$ 1032, 2004.

VITTI, M. C. D.; KLUGE, R. A.; YAMAMOTO, L. K.; JACOMINO, A. P. Comportamento da beterraba minimamente processada em diferentes espessuras de corte. Horticultura Brasileira, Brasília, v. 21, n. 4, p. 623-626, 2003.

VITTI, M. C. D.; SASAKI, F. F.; MIGUEL, P.; JACOMINO, A. P.; MORETTI, C. L.; KLUGE, R. A. Atividade respiratória e aspectos microbiológicos de cultivares de batatas minimamente processadas e armazenadas em diferentes temperaturas. Ciência Rural, Santa Maria, v. 40, n. 1, p. 208-212, 2010.

VITTI, M. C. D.; YAMAMOTO, L. K.; SASAKI, F. F.; AGUILA, J. S.; KLUGE, R. A.; JACOMINO, A. P. Quality of minimally processed beet roots stored in different temperatures. Brazilian Archives of Biology and Technology, Curitiba, v. 48, n. 4, p. 503-510, 2005.

WILEY, R. C. Minimally processed refrigerated fruits and vegetables. Nova York: Ed. Chapman \& Hall, 1994. $368 \mathrm{p}$. 
